\title{
Real-time and Doppler US after pediatric segmental liver transplantation
}

\section{Hepatic vein stenosis}

\author{
Lisa Suzuki • Ilka R. S. de Oliveira • Azzo Widman • \\ Nelson E. M. Gibelli • Francisco C. Carnevale • \\ João G. Maksoud • Anne M. Hubbard • \\ Giovanni G. Cerri
}

Published online: 4 July 2008

(C) Springer-Verlag 2008

\section{Erratum to: Pediatr Radiol \\ DOI 10.1007/s00247-007-0731-7}

The family name of the fourth author was spelled incorrectly. It should be Gibelli, not Gibeli.

The online version of the original article can be found at http://dx.doi. org/10.1007/s00247-007-0731-7.

L. Suzuki

Department of Radiology, Child Institute,

University of São Paulo Medical School,

São Paulo, Brazil

I. R. S. de Oliveira • G. G. Cerri

Department of Radiology,

University of São Paulo Medical School,

São Paulo, Brazil

\section{A. Widman}

Department of Digestive Surgery, Clinic Hospital,

University of São Paulo Medical School,

São Paulo, Brazil

N. E. M. Gibelli • J. G. Maksoud

Department of Pediatric Surgery, Child Institute,

University of São Paulo Medical School,

São Paulo, Brazil

F. C. Carnevale

Radiology Institute, Clinic Hospital,

University of São Paulo Medical School,

São Paulo, Brazil

L. Suzuki $(\varangle)$

R. Alves Guimarães, 623/132,

CEP 05410-001, São Paulo, Brazil

e-mail: Lisa.suzuki@gmail.com
A. M. Hubbard
Department of Radiology, University of Nebraska Medical Center,
Omaha, NE, USA 